Article

\title{
The Influence of Parasitic Components on LLC Resonant Converter
}

\author{
Fang Li®, Ruixiang Hao *, Haodong Lei $®$, Xinyi Zhang and Xiaojie You \\ School of Electrical Engineering, Beijing Jiaotong University, Beijing 100044, China; hahalifang@163.com (F.L.); \\ leihaodong@bjtu.edu.cn (H.L.); 17121536@bjtu.edu.cn (X.Z.); xjyou@bjtu.edu.cn (X.Y.) \\ * Correspondence: haorx@bjtu.edu.cn; Tel.: +86-137-1774-2934
}

Received: 29 September 2019; Accepted: 8 November 2019; Published: 12 November 2019

check for updates

\begin{abstract}
In recent years, the LLC resonant converter has been widely used in DC-DC conversion applications. However, the parasitic components of the LLC resonant converter have a significant impact in practical applications, such as influence on the conduction loss and the soft-switching of power devices, the voltage oscillation across rectifier diodes, the unregulated output voltage at light load condition and so on. It is hard to analyze the higher-order circuits by the conventional analysis methods. Focusing on the operational principle of the LLC converter with parasitic components, the differential equation model is presented and solved by the numerical method in this paper. The simulation results verify the correctness of the theoretical analysis. The causes of two different frequency oscillations and the voltage spike are clarified. The design considerations and a specific example of the LLC converter are given. The experimental results are consistent with the simulation results, and the soft-switching of primary-side switches can be achieved in the prototype.
\end{abstract}

Keywords: LLC resonant converter; parasitic components; differential equation model; numerical solution; design consideration

\section{Introduction}

The LLC resonant converter has been widely used in the electric vehicle charger, server power supply, and uninterrupted power supply conditions for its advantages, such as isolation, adjustable voltage, soft switching, high switching frequency, and high efficiency [1,2]. In the ideal case, the resonant inductance, resonant capacitance, and magnetizing inductance operate together to achieve energy transfer. Frequency modulation control with half duty cycle is usually adopted. And when the switching frequency is lower than the resonant frequency, zero voltage switching (ZVS) turn-on of primary-side switches and zero current switching (ZCS) turn-off of rectifier diodes can be achieved $[3,4]$.

However, in practical applications, the parasitic components of the LLC resonant converter have a significant impact. The secondary-side parasitic capacitance may influence the ZVS transient in the LLC resonant converter [5]. The transformer capacitance may have an impact on the conduction loss of primary-side switches, and the optimal dead time should be longer [6,7]. In the LLC converter with center-tapped transformer, unbalanced leakage inductances may cause the imbalanced rectifying currents $[8,9]$. At the switching transitions, the voltage oscillation across rectifier diode may emerge by the transformer leakage inductance and the parasitic capacitance $[10,11]$. The practical phenomena that the output voltage is unregulated at light load condition cannot be explained by the ideal analysis. The essential reason may be the effect of junction capacitances of rectifier diodes, or the output capacitances of primary-side switches [12-14].

Besides the fundamental harmonic approximation method, the graphical state-trajectory analysis method is clear and useful to analyze the resonant converters [15]. There are also some analysis methods based on time-domain solution [16,17]. However, if the output capacitance or other parasitic 
components are considered, the order of the circuit will be higher, and it is difficult to get the time domain solution. Hence, simplified analysis has been used, such as assuming that the current of magnetizing inductance and the voltage of resonant capacitance remain unchanged to ignore the resonant devices, or only considering a single or several parasitic components $[18,19]$. The consequence is that the analysis is partial and not accurate. While in the study of silicon carbide ( $\mathrm{SiC})$ metal oxide semiconductor field effect transistor (MOSFET) behavior, the circuit-level analytical model with device parameters and parasitic values is proposed $[20,21]$. That provides another referential analysis method for the LLC converter considering the parasitic components.

This paper mainly focuses on the analysis of the operational principle of the LLC converter that considers parasitic components comprehensively. Section 2 presents the full-bridge LLC resonant converter circuit with parasitic components. The differential equation models of each stages are established in Section 3. The numerical solutions are solved, and the waveforms are discussed in Section 4. Design considerations and an example of the LLC convert are given in Section 5. The conclusion is in Section 6.

\section{Equivalent Circuit of LLC Resonant Converter with Parasitic Components}

Figure 1 shows the circuit diagram of a full-bridge LLC resonant converter which considers the parasitic components. The circuit contains the resonant inductance $L_{r}$, resonant capacitance $C_{r}$, and magnetizing inductance $L_{m}$ of the transformer $T$, and also includes the output capacitance $C_{0}$. In addition to these four necessary ideal passive devices, the parasitic components needing to be considered are:

- the output capacitances of the primary-side SiC MOSFET devices, named as $C_{i n 1} \sim C_{i n 4}$;

- the equivalent capacitance $C_{e q}$ of the transformer;

- the junction capacitances of the rectifier diodes, named as $C_{01} \sim C_{02}$;

- the equivalent series inductance $L_{o k}$ of the output capacitance branch;

- the on-resistance of the switch and the parasitic resistance in the print circuit board (PCB) line of the primary circuit loop are combined and equaled to $R_{1}$; the influence of the diode voltage drop and the parasitic resistance of the secondary circuit are similarly combined and equaled to $R_{2}$.

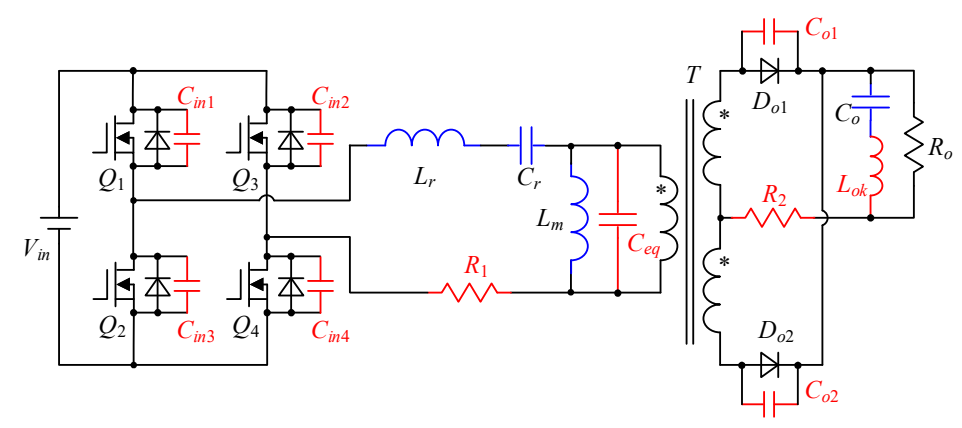

Figure 1. Full-bridge LLC resonant converter circuit with parasitic components.

\section{Analysis of Operational Principle with Parasitic Components}

The most common control strategy for LLC resonant converters is variable frequency control with half duty ratio. To make sure the converter is operating in the ZVS region, the switching frequency is usually lower than the resonant frequency. The circuit waveforms are shown in Figure 2, including the driving waveform $v_{g s}$, the voltage $v_{C i n 1}$ across the switch $Q_{1}$, the resonant current $i_{L r}$, and the voltage $v_{\mathrm{Co} 2}$ across the rectifier diode $D_{o 2}$. 


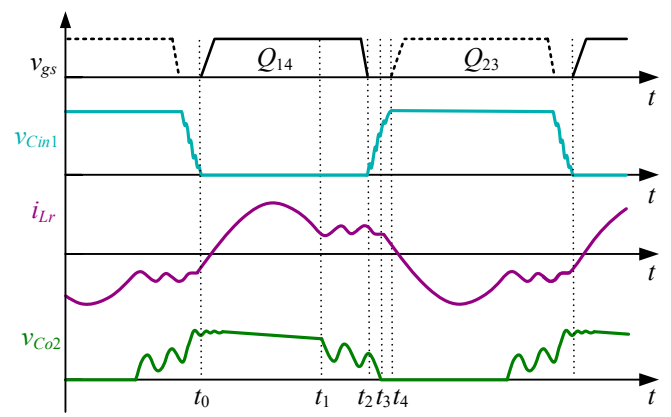

Figure 2. Key waveforms of full-bridge LLC resonant converter considering parasitic components.

There are several stages in the waveforms:

- $\left[t_{0}, t_{1}\right]$, positive resonant stage. $L_{r}$ resonates with $C_{r}$, and energy is transferred from the primary side to the secondary side. This stage ends when the resonant current is equal to the magnetizing current.

- $\left[t_{1}, t_{2}\right]$, since the switching period is longer than the resonance period, there is a freewheeling stage after the end of the resonance. In this stage, the statuses of switches are not changed, and the voltage applied to the resonant network is still $V_{i n}$. This stage ends when the switches $Q_{1}$ and $Q_{4}$ turn OFF.

- $\left[t_{2}, t_{4}\right]$ is the dead time. The voltage across the capacitances of the primary-side switches and the rectifier diodes are changing. This time interval is divided into two stages, the front voltage-establish stage and the rear voltage-establish stage. There are two different voltage-establish modes at different situations.

After $t_{4}$, the relative switches turn on, and the converter enters the negative resonant stage.

\subsection{Freewheeling Stage}

When the resonant current is equal to the magnetizing current, the current of the rectifier diode $D_{o 1}$ crosses to zero, and $D_{o 1}$ turns off naturally. Then the converter operates in the freewheeling stage, in which the input voltage of the resonant network is still $V_{i n}$ for the switches $Q_{1}$ and $Q_{4}$ are still on. The equivalent circuit in $\left[t_{1}, t_{2}\right]$ is shown in Figure 3.

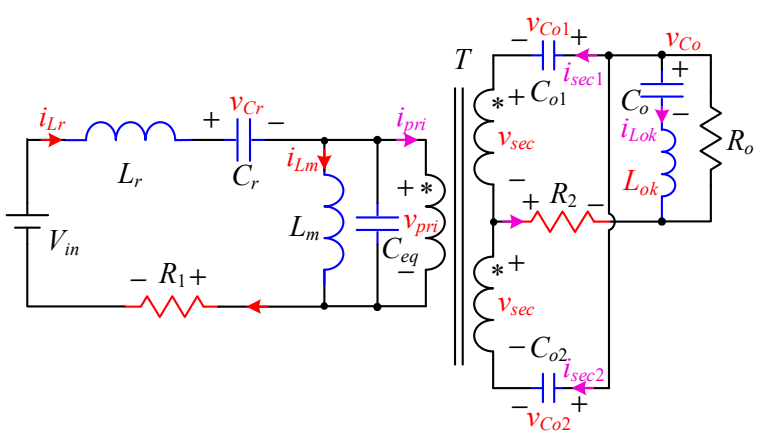

Figure 3. The equivalent circuit of the freewheeling stage.

Assume the voltage on the output capacitance is $v_{0}$, and $V_{R o}$ is the average voltage value on the load $R_{o}$ at steady state. Therefore, the initial voltages of $v_{C_{0} 1}$ and $v_{C_{0} 2}$ are 0 and $2 V_{R o}$ on the freewheeling stage. According to the positive direction shown in Figure 3, the relationships of voltages and currents of the LLC converter are list as Equation (A1) in the Appendix A. In which $i_{p r i}$ is the primary current of the transformer, $i_{\sec 1}$ and $i_{\sec 2}$ are the currents in the two secondary windings respectively. Equation (A1) is complicated and cannot be written as the matrix form directly. To 
simplify the analysis, several assumptions are made as follows: the voltage $V_{R o}$ is constant, and the voltage change rate of the secondary-side of the transformer is equal to the voltage change rates of $v_{\mathrm{C}_{0} 2}$ :

$$
\frac{d v_{s e c}}{d t}=\frac{1}{N} \frac{d v_{p r i}}{d t}=-\frac{d v_{C o 1}}{d t}=\frac{d v_{C o 2}}{d t}
$$

in which the transformer turns ratio is $N: 1: 1$. Therefore, the resonant current can be solved as:

$$
i_{L r}=i_{L m}+C_{e q} \frac{d v_{p r i}}{d t}+i_{p r i}=i_{L m}+\left(C_{e q}+\frac{C_{o 1}}{N^{2}}+\frac{C_{o 2}}{N^{2}}\right) \frac{d v_{p r i}}{d t} .
$$

The change rates of voltages are:

$$
\left\{\begin{array}{l}
\frac{d v_{p r i}}{d t}=\frac{i_{L r}-i_{L m}}{C_{A}} \\
\frac{d v_{C 01}}{d t}=-\frac{d v_{s e c}}{d t}=-\frac{1}{N} \frac{d v_{p r i}}{d t}=-\frac{1}{N} \frac{i_{L r}-i_{L m}}{C_{A}} \\
\frac{d v_{C 02}}{d t}=\frac{d v_{s e c}}{d t}=\frac{1}{N} \frac{d v_{p r i}}{d t}=\frac{1}{N} \frac{i_{L r}-i_{L m}}{C_{A}}
\end{array}\right.
$$

in which $C_{A}=\left(C_{e q}+\frac{C_{01}}{N^{2}}+\frac{C_{o 2}}{N^{2}}\right)$.

Then, the current change rate of output capacitance branch meets:

$$
L_{o k} \frac{d i_{L o k}}{d t}=-R_{0} C_{o 1} \frac{d v_{C o 1}}{d t}-R_{o} C_{o 2} \frac{d v_{C o 2}}{d t}-i_{L o k}-v_{C o} .
$$

In the end, the relationships of voltages and currents in the freewheeling stage can be written as the matrix form of differential equations and list in Equation (A2) in the Appendix A.

\subsection{Front Voltage-Establish Stage}

After the freewheeling stage, the primary switches $Q_{1}$ and $Q_{4}$ turn OFF, the voltages on capacitances of the primary-side switches and the rectifier diodes are both changing. The equivalent circuit of this stage is shown in Figure 4.

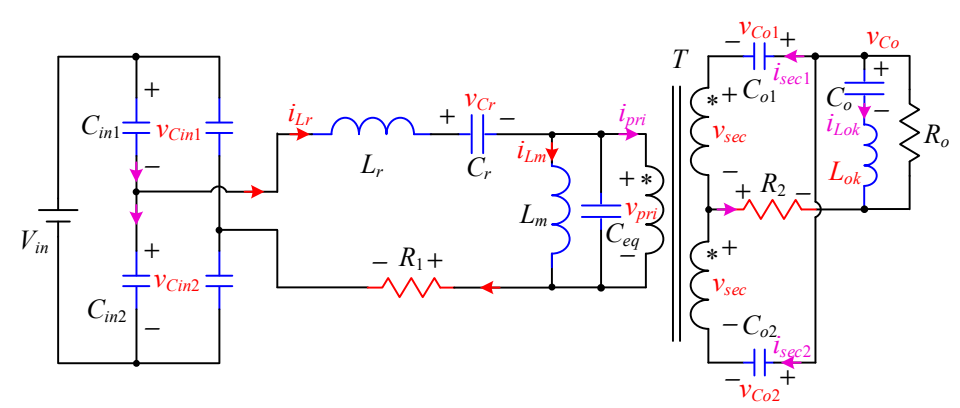

Figure 4. The equivalent circuit of the front voltage-establish stage.

In the traditional analysis, $C_{i n 1}$ and $C_{i n 2}$ are the same, and the currents in those capacitances are at the same value with the opposite direction. However, considering the variation of junction capacitances with the drain-source voltage $v_{d s}, C_{i n 1}$ and $C_{i n 2}$ are no longer equal for the initial voltage of $Q_{1}$ is 0 and the initial voltage of $Q_{2}$ is $V_{i n}$. And the currents of the capacitances are no longer same, which satisfy:

$$
i_{C i n 1}-i_{C i n 2}=i_{L r}
$$


Under variable frequency control with half duty ratio in the LLC converter, it can be considered that the voltage change of $Q_{4}$ is consistent with that of $Q_{1}$ synchronously. And $Q_{3}$ is the same as $Q_{2}$. Therefore, the calculation can be simplified and written as:

$$
\left\{\begin{array}{l}
\frac{d i_{L r}}{d t}=\frac{v_{C i n 2}-v_{C i n 1}-v_{C r}-v_{p r i}-R_{1} i_{L r}}{L_{r}} \\
\frac{d v_{p r i}}{d t}=\frac{i_{L r}-i_{L m}}{C_{A}}
\end{array} .\right.
$$

The matrix form of differential equations of voltages and currents are list in Equation (A3) in the Appendix A.

\subsection{Rear Voltage-Establish Stage}

The LLC converter enters to rear voltage-establish stage either $v_{\mathrm{Cin} 2}$ or $v_{\mathrm{C} 02}$ drops to zero in the front voltage-establish stage. However, the equivalent circuit became different in the next. Two situations need to be discussed separately: primary capacitance voltage-establish mode and secondary capacitance voltage-establish mode. No matter which mode the converter is operating in, after the rear voltage-establish stage, the converter reaches the same stage, i.e., the negative resonant stage.

\subsubsection{Primary Capacitance Voltage-Establish Mode}

At $t_{3}$, the voltage of $C_{02}$ drops to zero and $D_{02}$ turns on, and the primary-side voltage of the transformer drops to $-N V_{o}$ synchronously. Then the energy transfers from the primary side to the secondary side. The equivalent circuit of this mode is shown in Figure 5.

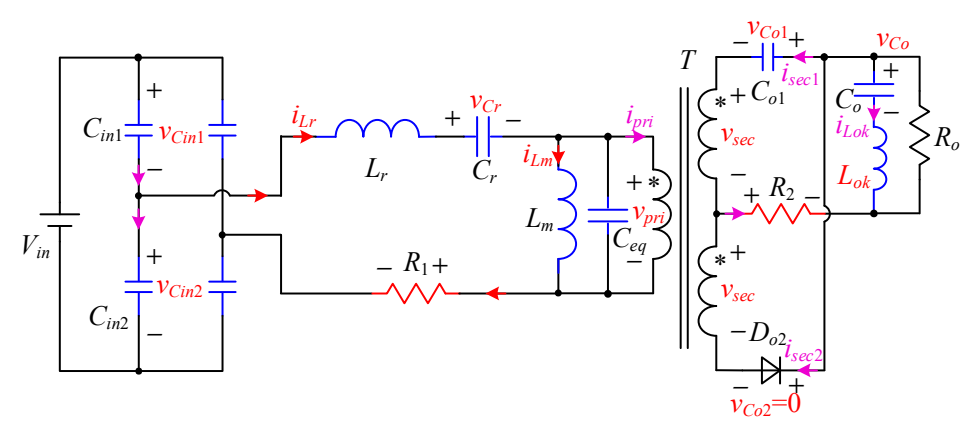

Figure 5. The equivalent circuit of the primary capacitance voltage-establish mode.

$D_{o 2}$ turns on and $v_{\mathrm{C}_{02}}=0$, then the secondary-side voltage of the transformer satisfies:

$$
v_{s e c}=-v_{C o 1}+v_{R o}+R_{2}\left(i_{L o k}+\frac{v_{R o}}{R_{o}}\right)=0-v_{R o}-R_{2}\left(i_{L o k}+\frac{v_{R o}}{R_{o}}\right) .
$$

Make simplification and get:

$$
\left\{\begin{array}{l}
v_{s e c}=-\left(\left(1+\frac{R_{2}}{R_{o}}\right) v_{R o}+R_{2} i_{L o k}\right)=-\frac{1}{2} v_{C o 1} \\
v_{R o}=\left(-v_{s e c}-R_{2} i_{L o k}\right) \frac{R_{o}}{R_{o}+R_{2}}=\left(-\frac{v_{p r i}}{N}-R_{2} i_{L o k}\right) \frac{R_{o}}{R_{o}+R_{2}}
\end{array} .\right.
$$

Because $v_{R o}$ is the sum of the voltages of the output capacitance and parasitic inductance, as:

$$
v_{R o}=v_{C o}+L_{o k} \frac{d i_{L o k}}{d t} .
$$

By calculating, the current changing rate of output capacitance branch is:

$$
\frac{d i_{L o k}}{d t}=-\frac{R_{o}}{N L_{o k}\left(R_{o}+R_{2}\right)} v_{p r i}-\frac{1}{L_{o k}} v_{C o}-\frac{R_{o} R_{2}}{L_{o k}\left(R_{o}+R_{2}\right)} i_{L o k} .
$$


The resonant current and the secondary-side currents are:

$$
\left\{\begin{array}{l}
i_{L r}=i_{L m}+C_{e q} \frac{d v_{p r i}}{d t}+i_{p r i}=i_{L m}+C_{e q} \frac{d v_{p r i}}{d t}-\frac{i_{s e c 1}}{N}+\frac{i_{s e c 2}}{N} \\
i_{s e c 1}=C_{o 1} \frac{d v_{c o 1}}{d t} \\
i_{s e c 2}=-i_{s e c 1}-i_{L o k}-\frac{v_{R o}}{R_{o}}
\end{array},\right.
$$

and the change rate of resonant current is:

$$
\frac{d i_{L r}}{d t}=\frac{v_{C i n 2}-v_{C i n 1}-v_{C r}-v_{p r i}-R_{1} i_{L r}}{L_{r}} .
$$

Then,

$$
\frac{d v_{p r i}}{d t}=\frac{i_{L r}-i_{L m}+\frac{1}{N} i_{L o k}-\frac{1}{N^{2}\left(R_{o}+R_{2}\right)} v_{p r i}-\frac{R_{2}}{N\left(R_{o}+R_{2}\right)} i_{L o k}}{C_{B}},
$$

in which $C_{B}=C_{e q}+\frac{4 C_{o 1}}{N^{2}}$. The matrix form of differential equations can be list as Equation (A4) in the Appendix A.

\subsubsection{Secondary Capacitance Voltage-Establish Mode}

The other possibility is that $v_{\operatorname{Cin} 1}$ and $v_{\operatorname{Cin} 2}$ change to $V_{\text {in }}$ and zero earlier, then the current is freewheeling through the body diodes of primary switches, and the voltage of the input-side of the resonant network is clamped to $-V_{i n}$. At this mode, since the secondary-side voltage of the transformer is lower than the output voltage, the diode $D_{o 2}$ is still reverse blocking. The equivalent circuit of secondary capacitance voltage-establish mode is shown in Figure 6.

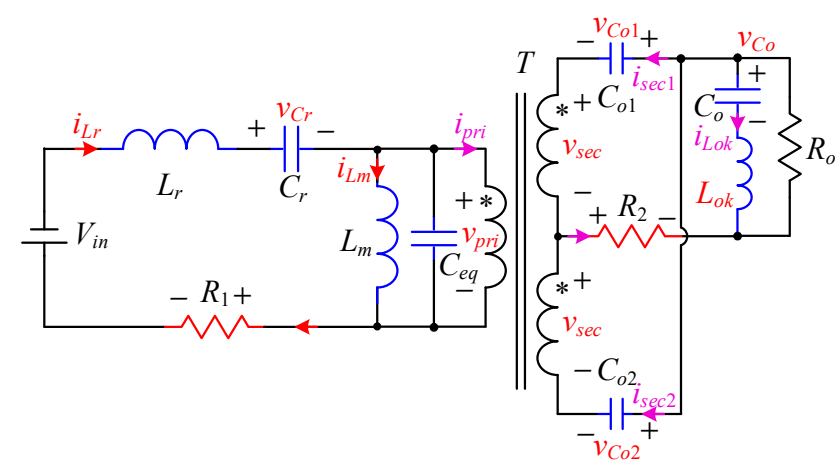

Figure 6. The equivalent circuit of the secondary capacitance voltage-establish mode.

Comparing the equivalent circuit of this mode to that of the free-wheeling stage, it can be found that only the voltage of the input-side of the resonant network changes from $V_{\text {in }}$ to $-V_{i n}$. Therefore, modify the corresponding coefficient of Equation (A2) can get the differential equations of secondary capacitance voltage-establish mode as Equation (A5) in the Appendix A.

\subsection{Negative Resonant Stage}

After the rear voltage-establish stage, the voltage of the input-side of the resonant network is clamped to $-V_{i n}$. The rectifier diode $D_{02}$ is conducting forward, and the energy is transferred from the input to the output of the converter. The equivalent circuit is shown in Figure 7. 


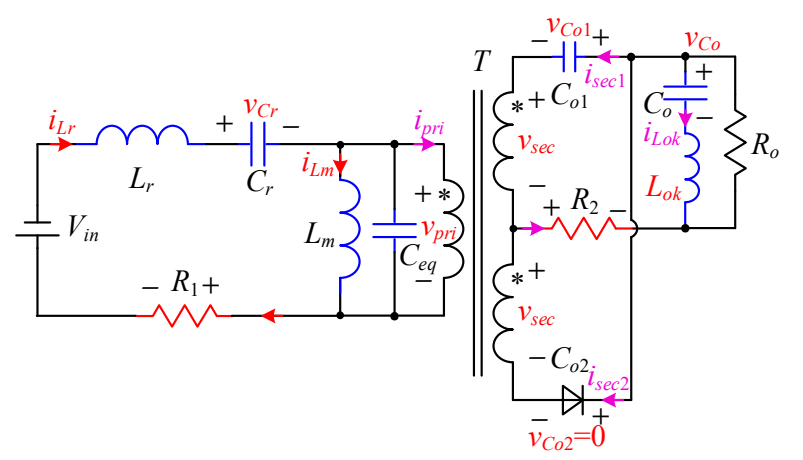

Figure 7. The equivalent circuit of the negative resonant stage.

The differences from Figure 7 to Figure 5 are the voltage of the input side of the resonant network becomes $-V_{i n}$, and the change rates of $v_{\operatorname{Cin} 1}$ and $v_{\operatorname{Cin} 2}$ are both zero. The differences from Figure 7 to Figure 6 are $v_{C_{02}}$ is clamped to zero, and $D_{02}$ is conducting forward. Then, the matrix form of differential equations of the negative resonant stage can be easily listed as Equation (A6) in the Appendix A.

In the negative resonant stage, the simplified analysis is adopted. No matter whether the primary-side switches $Q_{2}$ and $Q_{3}$ are on or not, the equivalent circuit is regarded as the same. The body diodes of primary-side switches could also conduct the resonant current. In practice, the voltage drop of body diode is much higher than that of the on-resistance of the switches. To improve efficiency, the body diode conducting time should be shortened.

In the ideal case, $L_{r}$ and $C_{r}$ are resonating during the resonant stage, and primary-side voltage of the transformer is reflected as $-N V_{o}$. With parasitic components, the negative resonant stage of the LLC converter becomes different. The damping oscillation between parasitic components and the voltage spikes and fluctuations may emerge. Those are both reflected on the voltages of the rectifier diode and the transformer. As a consequence, the voltage stress of the rectifier diodes will increase, and the output voltage will be distorted.

\section{Numerical Solution and Simulation Results}

\subsection{Numerical Solution}

Calculate the numerical solution of the differential equations in MATLAB, and Figure 8 shows the flow chart processes of the four stages after the positive resonant stage. The converter parameters and the voltage and current values at time $t_{1}$ are set at the initialization. Choose two different operating points of the LLC resonant converter to calculate, which correspond to the two kinds of modes. Then, draw the waveforms with changing time as shown in Figures 9 and 10.

In Figure $9, v_{\mathrm{Co} 2}$ drops to zero first, while in Figure 10, $v_{\mathrm{Cin} 2}$ drops to zero earlier. Besides the resonance between $L_{r}$ and $C_{r}$, there are two other oscillations in the waveforms of the numerical solution.

One oscillation is emerging in the freewheeling stage. The participant components are $L_{r}, L_{m}$, and the capacitance $C_{A}$. $C_{A}$ includes the $C_{e q}$ and the reflected capacitances of $C_{01}$ and $C_{02}$. It is hard to calculate the resonant frequency between these participant components. Since the value of $C_{A}$ is much smaller than the capacitance of $C_{r}$, the oscillation frequency is higher than the resonant frequency $f_{r}$ of the LLC converter. 


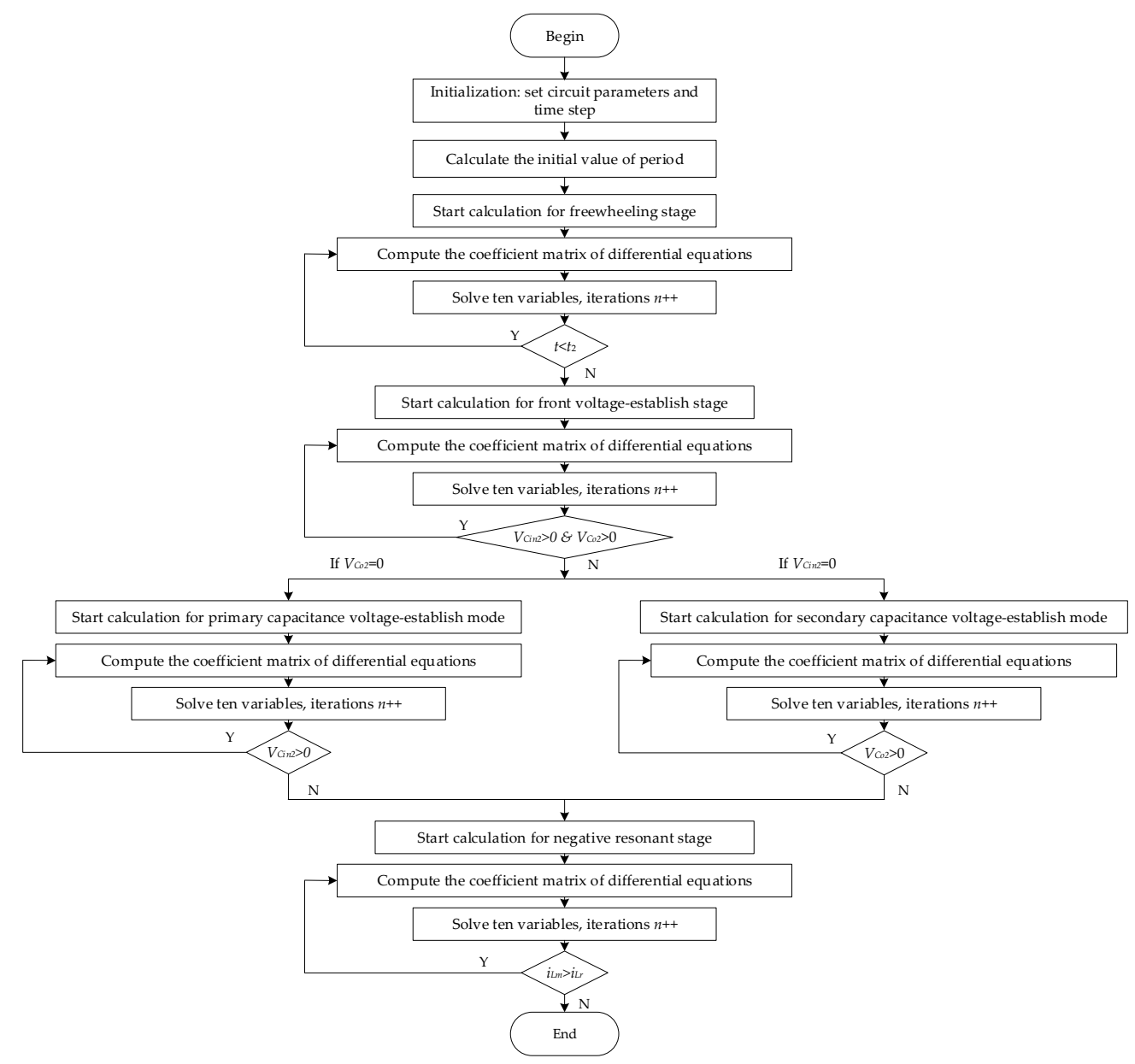

Figure 8. The flow chart of the solution processes in MATLAB.

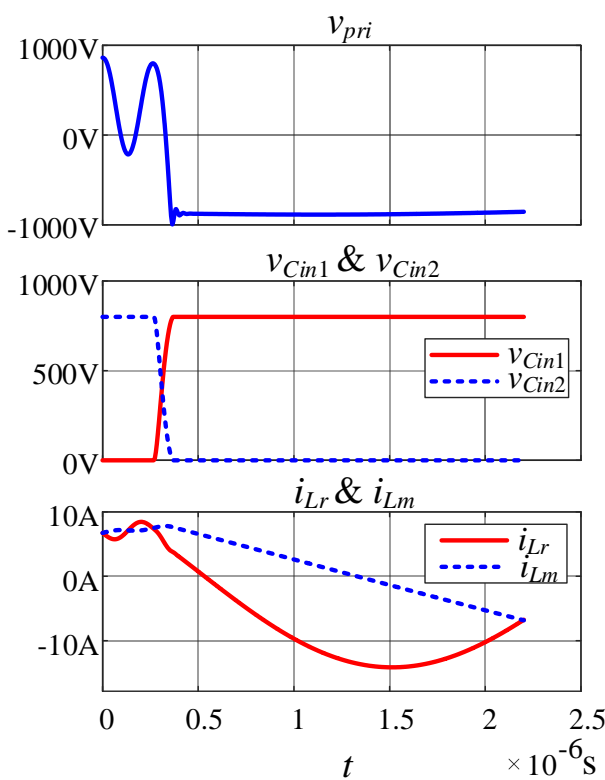

(a) Part one

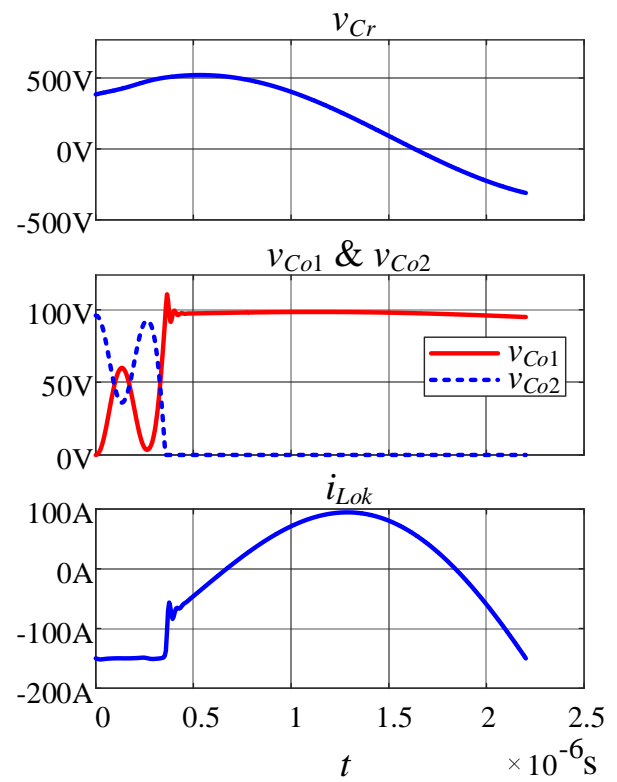

(b) Part two

Figure 9. The waveforms of the numerical solution with primary capacitance voltage-establish mode. 


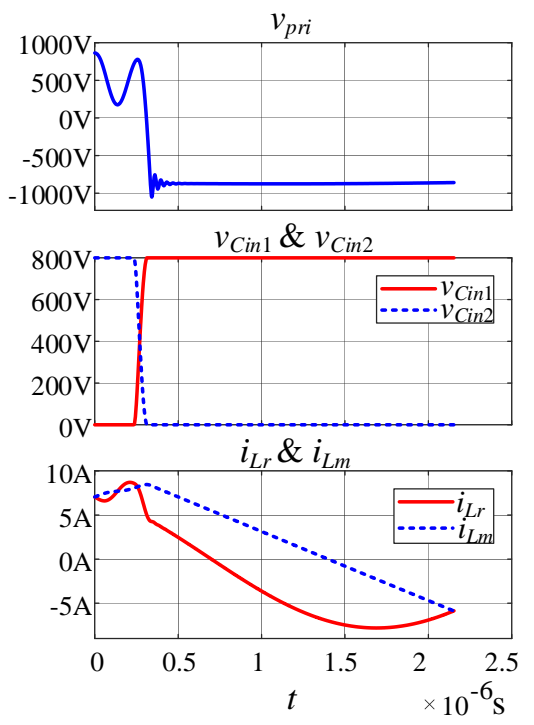

(a) Part one

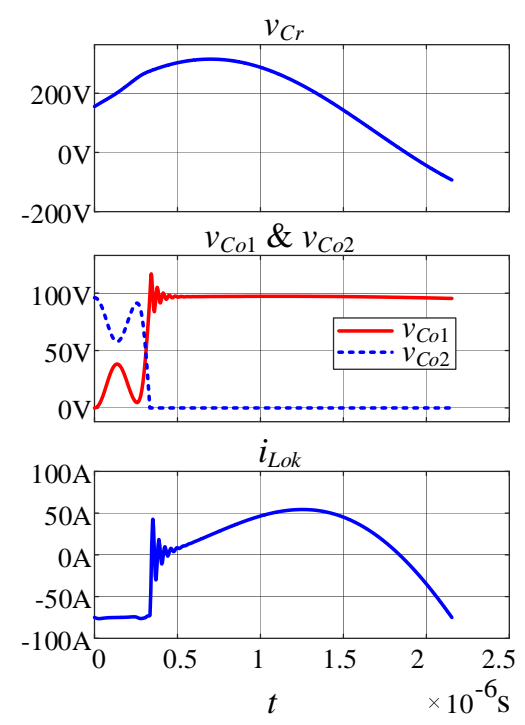

(b) Part two

Figure 10. The waveforms of the numerical solution with secondary capacitance voltage-establish mode.

The other oscillation is emerging after $v_{\mathrm{Co} 2}$ drops to zero. In Figure 9, the oscillation is in the primary capacitance voltage-establish mode. And in Figure 10, the oscillation is in the negative resonant stage. From the waveform of $i_{L o k}$, it can be seen that there is a significant current step at this time, which leads to a voltage spike. Then, the participant components start to oscillate. Since the parasitic inductance of output capacitance branch is little and the equivalent capacitance $C_{B}$ is small, the oscillation frequency is high. Under the damping effect of $R_{1}$ and $R_{2}$, the oscillation decays slowly, overlaying on the main resonance waveform. In Figure 10, due to the secondary capacitance voltage-establish mode, the difference value between the resonant current and the magnetizing current is more significant. As a consequence, a higher spike emerges on the diode voltage and output voltage.

It should be noted that there is an inevitable error, because the error of initial values exists and the influence of the dead time is not considered. Anyway, the deviation is small, and the calculation results of the numerical solution can reflect the operation of the LLC converter considering parasitic components.

\subsection{Simulation Results}

LTspice software is used to verify the theoretical analysis for it has the advantages such as being free, fast, and easy to converge. And the mathematical model of SiC devices can be imported to LTspice directly. The junction capacitance of the rectifier diode can be represented as a variable current source controlled by variable voltage. To simplify the simulation, the open-loop waveform is simulated with unique driving signals. The LTspice simulation waveforms corresponding to the two kinds of modes are shown in Figures 11 and 12, respectively. 


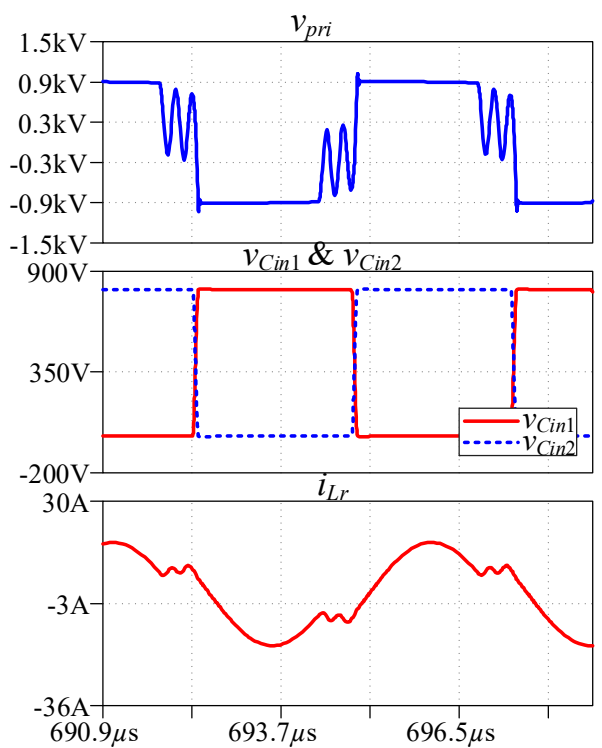

(a) Part one

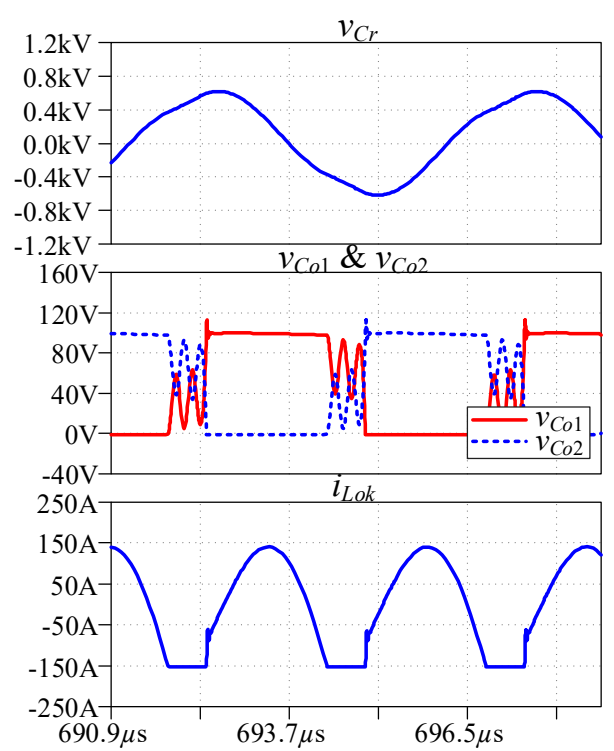

(b) Part two

Figure 11. The LTspice simulation results of the LLC converter with primary capacitance voltage-establish mode.

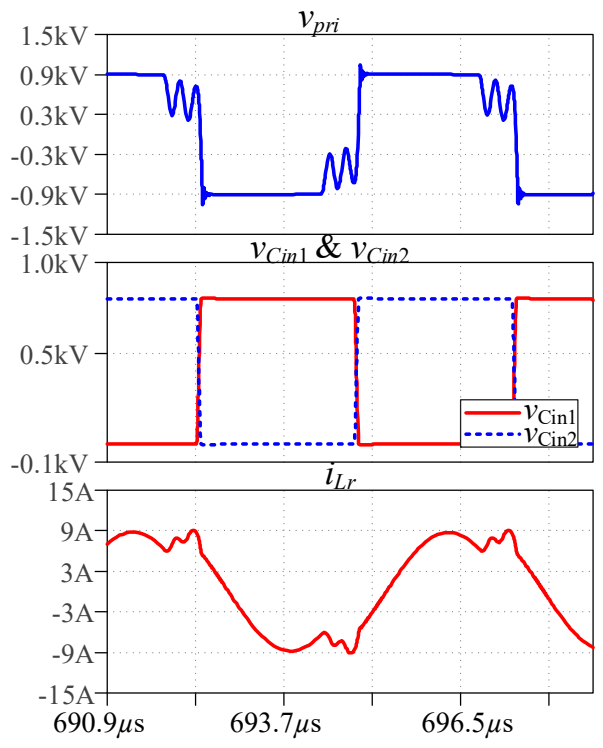

(a) Part one

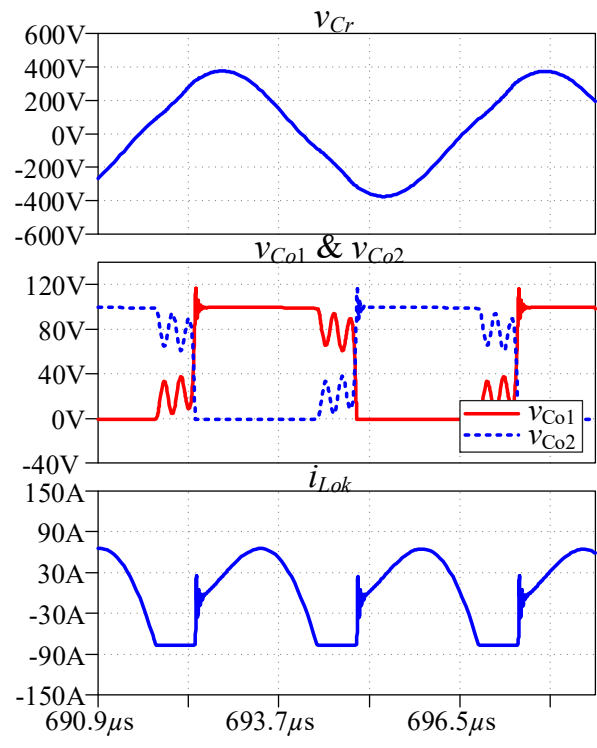

(b) Part two

Figure 12. The LTspice simulation results of the LLC converter with secondary capacitance voltage-establish mode.

In the LTspice simulation model, all of the parasitic components in the full-bridge LLC resonant converter circuit are considered. The magnetizing current cannot be extracted due to the coupling inductance model of the transformer in LTspice. Compared with the waveforms of the numerical solution of MATLAB, the results are mainly the same with two other oscillations and spikes. However, the length of the freewheeling stage set in the LTspice simulation is slightly larger than that of MATLAB, so the number of oscillation cycles is increased. 


\section{Design Considerations and Experimental Verification}

\subsection{Design Considerations of the LLC Converter}

Based on the differential equation model and the numerical results, some design considerations of the LLC converter can be given.

- The dead time for achieving the soft-switching of primary-side switches is related to their output capacitances. However, the output capacitance of switches changes with the drain-source voltage. In the datasheet, the output capacitance is usually given as a curve and the specific value of output capacitance under the specific test condition. In order to simplify the calculation, 2 or 3 times of the specific value of the output capacitance can be used as the equivalent output capacitance in general.

- The maximum load power should be used in designing the converter parameters. When the load power is maximum, $v_{c r}$ is high and $i_{L r}$ is low in the freewheeling stage. Thus, it is the most serious condition to realize soft-switching of the primary-side switches.

- The equivalent capacitance of the transformer and the junction capacitance of the rectifier diodes deteriorate the soft-switching of the primary-side switches, and they are both participating in the two oscillations. When designing transformers, the equivalent capacitance should be reduced seriously.

- The equivalent series inductance $L_{o k}$ of the output capacitance contributes to the voltage spike in the high frequency oscillation, especially for the situation with high output current. Therefore, the output capacitance with small equivalent series inductance should be selected, and the parasitic inductance of the circuit loop should be minimized.

\subsection{Experimental Results}

In order to verify the assistance of this paper on the design and application of the LLC converter, the specific and concise design procedure based on an application example is given. The design requirements are shown in Table 1.

Table 1. The parameters of the LLC experimental prototype.

\begin{tabular}{cc}
\hline Parameters & Value \\
\hline Input voltage & $700-800 \mathrm{~V}$ \\
Output voltage & $48 \mathrm{~V}$ \\
Rated power & $8000 \mathrm{~W}$ \\
Primary switches & C2M0025120D \\
Rectifier diodes & VB60170G \\
\hline
\end{tabular}

According to the relationship of the input and output voltages, the transformer turns ratio is defined as 18:1:1. The LLC converter works below the resonant frequency. Set the resonant frequency $f_{r}$ as $255 \mathrm{kHz}$, and the dead time between switches $t_{\text {dead }}$ is $300 \mathrm{~ns}$. The primary-side switches are $\mathrm{SiC}$ MOSFETs C2M0025120D. In the datasheet, the output capacitance $C_{o s s}$ is $220 \mathrm{pF}$ under the test condition as $v_{g s}=0 \mathrm{~V}, v_{d s}=1100 \mathrm{~V}, f=1 \mathrm{MHz}$, and $v_{A C}=25 \mathrm{mV}$.

The traditional LLC resonant converter parameter design process has been given in the references [22,23]. Ignoring the voltage drop of the rectifier diodes, the amplitude of magnetizing current at resonant frequency can be calculated as:

$$
I_{L m}=\frac{1}{2} \frac{N V_{R o}}{L_{m}} \frac{1}{2 f_{r}} .
$$


The required dead time to charge and discharge the $C_{o s s}$ is:

$$
t_{\text {dead }}=2 C_{o s s} \frac{V_{\text {in }}}{I_{L m}} .
$$

Therefore, the upper limit value of $L_{m}$ satisfies:

$$
\frac{1}{2} \frac{N V_{R o}}{L_{m}} \frac{1}{2 f_{r}}=2 C_{\text {oss }} \frac{V_{\text {in }}}{t_{\text {dead }}} .
$$

By calculating the parameters of the LLC converter, $L_{m}$ should be less than $668 \mu \mathrm{H}$. However, the soft-switching of primary-side switches cannot be achieved due to the loose restrictions. According to the design considerations proposed in this paper, the actual value of $L_{m}$ is taken as one sixth to one quarter of the upper limit value calculated by Equation (16), considering the influence of the output capacitance of switches, transformer equivalent parasitic capacitance, and diode junction capacitance. Based on the switching frequency range $160-250 \mathrm{kHz}$ and the voltage gain curves under different switching frequencies, $L_{m}$ is determined as 6-7 times of $L_{r}$ in the prototype. Therefore, the final value of $L_{r}$ is $19.18 \mu \mathrm{H}$, and $L_{m}$ is $111.4 \mu \mathrm{H}$. According to the resonant frequency, the value of $C_{r}$ is $20.25 \mathrm{nF}$.

In the final design of the prototype, there are two transformers whose primary windings are in series and secondary windings are in parallel after rectifier diodes. The two transformers are the same, in which the turns ratio is 18:2:2 and magnetizing inductances is $55.7 \mu \mathrm{H}$. In the design process, the equivalent parasitic capacitance of the transformer should be minimized. When the PCB is drawn, the length of the secondary circuit should be minimized to reduce parasitic inductance. And the symmetry of each secondary circuit should be guaranteed. Those specific optimization methods will not be detailed here. Figure 13 shows the experimental prototype of the LLC converter.

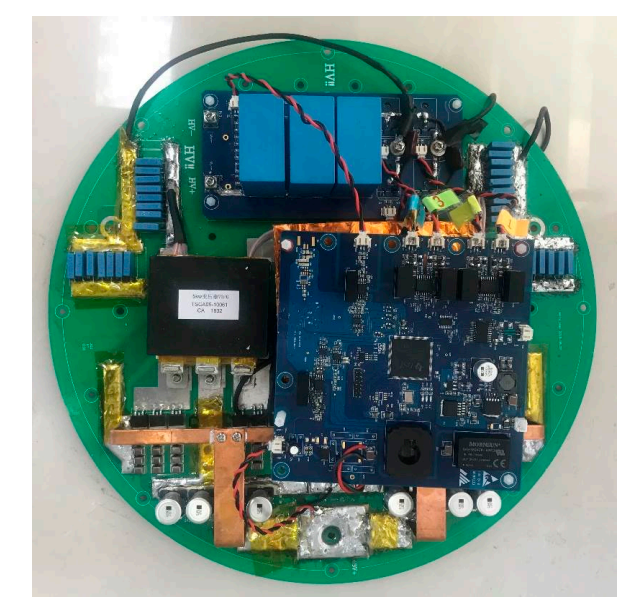

Figure 13. The experimental prototype of the LLC converter.

The experimental results of the LLC converter are shown in Figure 14. In case one, the time interval of the freewheeling stage is longer. And $i_{L r}$ and $v_{\mathrm{CO} 2}$ are oscillating at a frequency higher than the resonant frequency of the LLC converter. $v_{C_{0} 2}$ drops to zero first, and then $v_{\operatorname{Cin} 2}$ drops to zero. When the rectifier diode is conducting forward, there is high-frequency oscillation in the beginning of the resonant stage. It is corresponding to the numerical solution and the simulation results. In case two, the time interval of the freewheeling stage is shorter and less than a resonant period. $v_{\operatorname{Cin} 2}$ drops to zero a little earlier than $v_{\mathrm{Co} 2}$. The spike of high-frequency oscillation in the waveforms of diode voltage is a little larger than that of case one. 


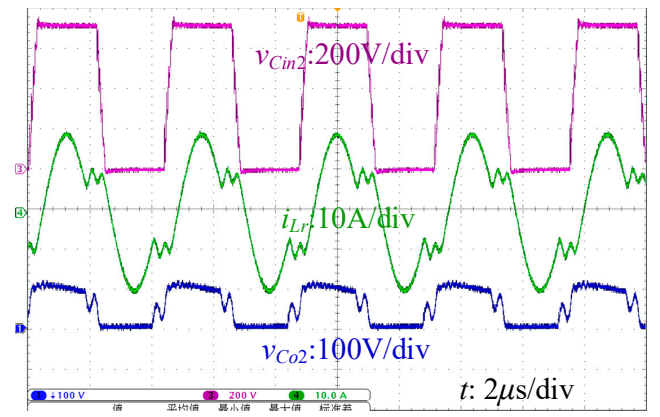

(a) Case one

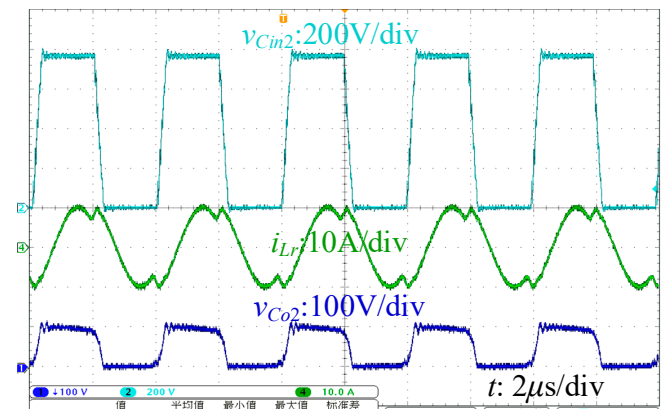

(b) Case two

Figure 14. The experimental results of the LLC converter.

The experiment results verify the correctness of the differential equation model and its numerical solution. What's more, the soft-switching of primary-side MOSFETs is achieved based on the parameter design considerations proposed in this paper.

\section{Conclusions}

The operational principle of the LLC resonant converter with parasitic components is proposed in this paper. Besides the three resonant components, the output capacitance and its parasitic inductance, the capacitance of primary-side switches, the capacitance of rectifier diodes, and the equivalent capacitance of the transformer are all considered. By establishing differential equations and solving numerical solutions, the causes of two different frequency oscillations and the voltage spike are clarified. The simulation results verify the correctness of the theoretical analysis. The influence of the parasitic components and the design considerations are proposed. The experimental results of a specific example of the LLC converter are given. The analysis is helpful in the design and application of the LLC converter.

Author Contributions: F.L., conceptualization, methodology, writing-review and editing; R.H. and X.Y., resources and supervision; H.L., formal analysis, investigation, and validation; X.Z., software and writing-original draft.

Funding: This research was funded by China Postdoctoral Science Foundation (Grant NO. 2019M650466), the Fundamental Research Funds for the Central Universities (Grant No. 2017JBZ101) and the Fundamental Research Funds for the Central Universities (Grant No. 2017YJS176).

Conflicts of Interest: The authors declare no conflict of interest.

\section{Appendix A}

The voltage and current expressions of freewheeling stage:

$$
\left\{\begin{array}{l}
V_{i n}=L_{r} \frac{d i_{L r}}{d t}+v_{C r}+v_{p r i}+R_{1} i_{L r} \\
i_{L r}=i_{L m}+C_{e q} \frac{d v_{p r i}}{d t}+i_{p r i} \\
v_{p r i}=L_{m} \frac{d i_{L m}}{d t} \\
i_{L r}=C_{r} \frac{d v_{c r}}{d t} \\
v_{C i n 1}=0, v_{C i n 2}=V_{i n} \\
v_{s e c}=-v_{C o 1}+v_{R o}+R_{2}\left(i_{L o k}+\frac{v_{R o}}{R_{o}}\right), v_{p r i}=N v_{s e c} \\
v_{s e c}=v_{C o 2}-v_{R o}-R_{2}\left(i_{L o k}+\frac{v_{R o}}{R_{o}}\right) \\
i_{s e c 1}=C_{o 1} \frac{d v_{C o 1}}{d t}, i_{s e c 2}=C_{o 2} \frac{d v_{C o 2}}{d t} \\
i_{p r i}=-\frac{i_{s e c 1}}{N}+\frac{i_{s e c 2}}{N} \\
C_{o} \frac{d v_{C o}}{d t}=i_{L o k} \\
v_{R o}=v_{C o}+L_{o k} \frac{d i_{L o k}}{d t}=R_{o}\left(-C_{o 1} \frac{d v_{C o 1}}{d t}-C_{o 2} \frac{d v_{C o 2}}{d t}-i_{L o k}\right)
\end{array} .\right.
$$


The differential equation model of freewheeling stage:

$$
\left(\begin{array}{c}
\dot{i}_{L r} \\
\dot{v}_{C r} \\
\dot{i}_{L m} \\
\dot{v}_{p r i} \\
\dot{v}_{C i n 1} \\
\dot{v}_{C i n 2} \\
\dot{v}_{C o 1} \\
\dot{v}_{C o 2} \\
\dot{i}_{L o k} \\
\dot{v}_{C o}
\end{array}\right)=\left(\begin{array}{cccccccccc}
\frac{-R_{1}}{L_{r}} & \frac{-1}{L_{r}} & 0 & \frac{-1}{L_{r}} & 0 & 0 & 0 & 0 & 0 & 0 \\
\frac{1}{C_{r}} & 0 & 0 & 0 & 0 & 0 & 0 & 0 & 0 & 0 \\
0 & 0 & 0 & \frac{1}{L_{m}} & 0 & 0 & 0 & 0 & 0 & 0 \\
\frac{1}{C_{A}} & 0 & \frac{-1}{C_{A}} & 0 & 0 & 0 & 0 & 0 & 0 & 0 \\
0 & 0 & 0 & 0 & 0 & 0 & 0 & 0 & 0 & 0 \\
0 & 0 & 0 & 0 & 0 & 0 & 0 & 0 & 0 & 0 \\
\frac{-1}{N C_{A}} & 0 & \frac{1}{N C_{A}} & 0 & 0 & 0 & 0 & 0 & 0 & 0 \\
\frac{1}{N C_{A}} & 0 & \frac{-1}{N C_{A}} & 0 & 0 & 0 & 0 & 0 & 0 & 0 \\
\frac{R_{o}\left(C_{o 1}-C_{o 2}\right)}{N C_{A} L_{o k}} & 0 & \frac{-R_{o}\left(C_{o 1}-C_{02}\right)}{N C_{A} L_{o k}} & 0 & 0 & 0 & 0 & 0 & \frac{-R_{o}}{L_{o k}} & \frac{-1}{L_{o k}} \\
0 & 0 & 0 & 0 & 0 & 0 & 0 & 0 & \frac{1}{C_{o}} & 0
\end{array}\right)\left(\begin{array}{c}
i_{L r} \\
v_{C r} \\
i_{L m} \\
v_{p r i} \\
v_{C i n 1} \\
v_{C i n 2} \\
v_{C o 1} \\
v_{C o 2} \\
i_{L o k} \\
v_{C o}
\end{array}\right)+\left(\begin{array}{c}
\frac{V_{i n}}{L_{r}} \\
0 \\
0 \\
0 \\
0 \\
0 \\
0 \\
0 \\
0 \\
0
\end{array}\right)
$$

The differential equation model of front voltage-establish stage:

$$
\left(\begin{array}{c}
\dot{i}_{L r} \\
\dot{v}_{C r} \\
\dot{i}_{L m} \\
\dot{v}_{p r i} \\
\dot{v}_{C i n 1} \\
\dot{v}_{C i n 2} \\
\dot{v}_{C o 1} \\
\dot{v}_{C o 2} \\
\dot{i}_{L o k} \\
\dot{v}_{C o}
\end{array}\right)=\left(\begin{array}{cccccccccc}
\frac{-R_{1}}{L_{r}} & \frac{-1}{L_{r}} & 0 & \frac{-1}{L_{r}} & \frac{-1}{L_{r}} & \frac{1}{L_{r}} 0 & 0 & 0 & 0 & 0 \\
\frac{1}{C_{r}} & 0 & 0 & 0 & 0 & 0 & 0 & 0 & 0 & 0 \\
0 & 0 & 0 & \frac{1}{L_{m}} & 0 & 0 & 0 & 0 & 0 & 0 \\
\frac{1}{C_{A}} & 0 & \frac{-1}{C_{A}} & 0 & 0 & 0 & 0 & 0 & 0 & 0 \\
\frac{1}{C_{i n 1}+C_{i n 2}} & 0 & 0 & 0 & 0 & 0 & 0 & 0 & 0 & 0 \\
\frac{-}{C_{i n 1}+C_{i n 2}} & 0 & 0 & 0 & 0 & 0 & 0 & 0 & 0 & 0 \\
\frac{-1}{N C_{A}} & 0 & \frac{1}{N C_{A}} & 0 & 0 & 0 & 0 & 0 & 0 & 0 \\
\frac{1}{N C_{A}} & 0 & \frac{-1}{N C_{A}} & 0 & 0 & 0 & 0 & 0 & 0 & 0 \\
\frac{R_{o}\left(C_{o 1}-C_{o 2}\right)}{N C_{A} L_{o k}} & 0 & \frac{-R_{o}\left(C_{C_{1}}-C_{o 2}\right)}{N C_{A} L_{o k}} & 0 & 0 & 0 & 0 & 0 & \frac{-R_{o}}{L_{o k}} & \frac{-1}{L_{o k}} \\
0 & 0 & 0 & 0 & 0 & 0 & 0 & 0 & \frac{1}{C_{o}} & 0
\end{array}\right)\left(\begin{array}{c}
i_{L r} \\
v_{C r} \\
i_{L m} \\
v_{p r i} \\
v_{C i n 1} \\
v_{C i n 2} \\
v_{C o 1} \\
v_{C o 2} \\
i_{L o k} \\
v_{C o}
\end{array}\right)+\left(\begin{array}{l}
0 \\
0 \\
0 \\
0 \\
0 \\
0 \\
0 \\
0 \\
0 \\
0
\end{array}\right) .
$$

The differential equation model of rear voltage-establish stage with primary capacitance voltage-establish mode:

$$
\left(\begin{array}{c}
\dot{i}_{L r} \\
\dot{v}_{C r} \\
\dot{i}_{L m} \\
\dot{v}_{p r i} \\
\dot{v}_{C i n 1} \\
\dot{v}_{C i n 2} \\
\dot{v}_{C o 1} \\
\dot{v}_{C o 2} \\
\dot{i}_{L o k} \\
\dot{v}_{C o}
\end{array}\right)=\left(\begin{array}{cccccccccc}
\frac{-R_{1}}{L_{r}} & \frac{-1}{L_{r}} & 0 & \frac{-1}{L_{r}} & \frac{-1}{L_{r}} & \frac{1}{L_{r}} & 0 & 0 & 0 & 0 \\
\frac{1}{C_{r}} & 0 & 0 & 0 & 0 & 0 & 0 & 0 & 0 & 0 \\
0 & 0 & 0 & \frac{1}{L_{m}} & 0 & 0 & 0 & 0 & 0 & 0 \\
\frac{1}{C_{B}} & 0 & \frac{-1}{C_{B}} & \frac{-1}{N^{2} C_{B}\left(R_{o}+R_{2}\right)} & 0 & 0 & 0 & 0 & \frac{R_{o}}{N C_{B}\left(R_{o}+R_{2}\right)} & 0 \\
\frac{1}{C_{i n 1}+C_{i n 2}} & 0 & 0 & 0 & 0 & 0 & 0 & 0 & 0 & 0 \\
\frac{-}{C_{i n 1}+C_{i n 2}} & 0 & 0 & 0 & 0 & 0 & 0 & 0 & 0 & 0 \\
-\frac{2}{N C_{B}} & 0 & \frac{2}{N C_{B}} & \frac{2}{N^{3} C_{B}\left(R_{o}+R_{2}\right)} & 0 & 0 & 0 & 0 & \frac{-2 R_{o}}{N^{2} C_{B}\left(R_{o}+R_{2}\right)} & 0 \\
0 & 0 & 0 & 0 & 0 & 0 & 0 & 0 & 0 & 0 \\
0 & 0 & 0 & -\frac{R_{o}}{N L_{o k}\left(R_{o}+R_{2}\right)} & 0 & 0 & 0 & 0 & -\frac{R_{o} R_{2}}{L_{o k}\left(R_{o}+R_{2}\right)} & \frac{-1}{L_{o k}} \\
0 & 0 & 0 & 0 & 0 & 0 & 0 & 0 & \frac{1}{C_{o}} & 0
\end{array}\right)\left(\begin{array}{c}
i_{L r} \\
v_{C r} \\
i_{L m} \\
v_{p r i} \\
v_{C i n 1} \\
v_{C i n 2} \\
v_{C o 1} \\
v_{C o 2} \\
i_{L o k} \\
v_{C o}
\end{array}\right)+\left(\begin{array}{l}
0 \\
0 \\
0 \\
0 \\
0 \\
0 \\
0 \\
0 \\
0 \\
0
\end{array}\right) .
$$


The differential equation model of rear voltage-establish stage with secondary capacitance voltage-establish mode:

$$
\left(\begin{array}{c}
\dot{i}_{L r} \\
\dot{v}_{C r} \\
\dot{i}_{L m} \\
\dot{v}_{p r i} \\
\dot{v}_{C i n 1} \\
\dot{v}_{C i n 2} \\
\dot{v}_{C o 1} \\
\dot{v}_{C o 2} \\
\dot{i}_{L o k} \\
\dot{v}_{C o}
\end{array}\right)=\left(\begin{array}{cccccccccc}
\frac{-R_{1}}{L_{r}} & \frac{-1}{L_{r}} & 0 & \frac{-1}{L_{r}} & 0 & 0 & 0 & 0 & 0 & 0 \\
\frac{1}{C_{r}} & 0 & 0 & 0 & 0 & 0 & 0 & 0 & 0 & 0 \\
0 & 0 & 0 & \frac{1}{L_{m}} & 0 & 0 & 0 & 0 & 0 & 0 \\
\frac{1}{C_{A}} & 0 & \frac{-1}{C_{A}} & 0 & 0 & 0 & 0 & 0 & 0 & 0 \\
0 & 0 & 0 & 0 & 0 & 0 & 0 & 0 & 0 & 0 \\
0 & 0 & 0 & 0 & 0 & 0 & 0 & 0 & 0 & 0 \\
\frac{-1}{N C_{A}} & 0 & \frac{1}{N C_{A}} & 0 & 0 & 0 & 0 & 0 & 0 & 0 \\
\frac{1}{N C_{A}} & 0 & \frac{-1}{N C_{A}} & 0 & 0 & 0 & 0 & 0 & 0 & 0 \\
\frac{R_{o}\left(C_{o 1}-C_{o 2}\right)}{N C_{A} L_{o k}} & 0 & \frac{-R_{o}\left(C_{o 1}-C_{o 2}\right)}{N C_{A} L_{o k}} & 0 & 0 & 0 & 0 & 0 & \frac{-R_{o}}{L_{o k}} & \frac{-1}{L_{o k}} \\
0 & 0 & 0 & 0 & 0 & 0 & 0 & 0 & \frac{1}{C_{o}} & 0
\end{array}\right)\left(\begin{array}{c}
i_{L r} \\
v_{C r} \\
i_{L m} \\
v_{p r i} \\
v_{C i n 1} \\
v_{C i n 2} \\
v_{C o 1} \\
v_{C o 2} \\
i_{L o k} \\
v_{C o}
\end{array}\right)+\left(\begin{array}{c}
-\frac{V_{i n}}{L_{r}} \\
0 \\
0 \\
0 \\
0 \\
0 \\
0 \\
0 \\
0 \\
0
\end{array}\right) .
$$

The differential equation model of negative resonant stage:

$$
\left(\begin{array}{c}
\dot{i}_{L r} \\
\dot{v}_{C r} \\
\dot{i}_{L m} \\
\dot{v}_{p r i} \\
\dot{v}_{C i n 1} \\
\dot{v}_{C i n 2} \\
\dot{v}_{C o 1} \\
\dot{v}_{C o 2} \\
\dot{i}_{L o k} \\
\dot{v}_{C o}
\end{array}\right)=\left(\begin{array}{cccccccccc}
\frac{-R_{1}}{L_{r}} & \frac{-1}{L_{r}} & 0 & \frac{-1}{L_{r}} & 0 & 0 & 0 & 0 & 0 & 0 \\
\frac{1}{C_{r}} & 0 & 0 & 0 & 0 & 0 & 0 & 0 & 0 & 0 \\
0 & 0 & 0 & \frac{1}{L_{m}} & 0 & 0 & 0 & 0 & 0 & 0 \\
\frac{1}{C_{B}} & 0 & \frac{-1}{C_{B}} & \frac{-1}{N^{2} C_{B}\left(R_{o}+R_{2}\right)} & 0 & 0 & 0 & 0 & \frac{R_{o}}{N C_{B}\left(R_{o}+R_{2}\right)} & 0 \\
0 & 0 & 0 & 0 & 0 & 0 & 0 & 0 & 0 & 0 \\
0 & 0 & 0 & 0 & 0 & 0 & 0 & 0 & 0 & 0 \\
-\frac{2}{N C_{B}} & 0 & \frac{2}{N C_{B}} & \frac{2}{N^{3} C_{B}\left(R_{o}+R_{2}\right)} & 0 & 0 & 0 & 0 & \frac{-2 R_{o}}{N^{2} C_{B}\left(R_{o}+R_{2}\right)} & 0 \\
0 & 0 & 0 & 0 & 0 & 0 & 0 & 0 & 0 & 0 \\
0 & 0 & 0 & -\frac{R_{o}}{N L_{o k}\left(R_{o}+R_{2}\right)} & 0 & 0 & 0 & 0 & -\frac{R_{o} R_{2}}{L_{o k}\left(R_{o}+R_{2}\right)} & \frac{-1}{L_{o k}} \\
0 & 0 & 0 & 0 & 0 & 0 & 0 & 0 & \frac{1}{C_{o}} & 0
\end{array}\right)\left(\begin{array}{c}
i_{L r} \\
v_{C r} \\
i_{L m} \\
v_{p r i} \\
v_{C i n 1} \\
v_{C i n 2} \\
v_{C o 1} \\
v_{C o 2} \\
i_{L o k} \\
v_{C o}
\end{array}\right)+\left(\begin{array}{c}
\frac{-V_{i n}}{L_{r}} \\
0 \\
0 \\
0 \\
0 \\
0 \\
0 \\
0 \\
0 \\
0
\end{array}\right) .
$$

\section{References}

1. Bhuvaneswari, C.; Babu, R.S.R. A review on LLC Resonant Converter. In Proceedings of the International Conference on Computation of Power, Energy Information and Communication (ICCPEIC), Chennai, India, 20-21 April 2016; pp. 620-623.

2. Lu, B.; Liu, W.; Liang, Y.; Lee, F.C.; Wyk, J.D. Optimal design methodology for LLC resonant converter. In Proceedings of the Twenty-First Annual IEEE Applied Power Electronics Conference and Exposition, 2006. APEC '06, Dallas, TX, USA, 3 March 2006; pp. 533-538.

3. Yang, B.; Lee, F.C.; Zhang, A.J.; Huang, G. Resonant converter for front end DC/DC conversion. In Proceedings of the APEC. Seventeenth Annual IEEE Applied Power Electronics Conference and Exposition (Cat. No.02CH37335), Dallas, TX, USA, 10-14 March 2002; Volume 2, pp. 1108-1112.

4. Gu, Y.; Lu, Z.Y.; Hang, L.J.; Qian, Z.M.; Huang, G.S. Three-level LLC series resonant DC/DC converter. IEEE Trans. Power Electron. 2005, 20, 781-789. [CrossRef]

5. Chen, $\mathrm{H}$.; $\mathrm{Wu}, \mathrm{X}$. Analysis on the influence of the secondary parasitic capacitance to ZVS transient in LLC resonant converter. In Proceedings of the 2014 IEEE Energy Conversion Congress and Exposition (ECCE), Pittsburgh, PA, USA, 14-18 September 2014; pp. 4755-4760.

6. Wang, N.; Jia, H.; Tian, M.; Li, Z.; Xu, G.; Yang, X. Impact of transformer stray capacitance on the conduction loss in a GaN-based LLC resonant converter. In Proceedings of the 2017 IEEE 3rd International Future Energy Electronics Conference and ECCE Asia (IFEEC 2017 - ECCE Asia), Kaohsiung, Taiwan, 3-7 June 2017; pp. 1334-1338.

7. Wang, N.; Yang, X.; Tian, M.; Jia, H.; Xu, G.; Li, Z. An Optimal Design Method Considering Transformer Parasitic Capacitance of LLC Resonant Converters. In Proceedings of the 2018 International Power Electronics Conference (IPEC-Niigata 2018_ECCE Asia), Niigata, Japan, 20-24 May 2018; pp. 998-1003.

8. Sato, M.; Nagaoka, S.; Uematsu, S.; Zaitsu, T. Mechanism of Current Imbalance in LLC resonant converter with Center Tapped Transformer. In Proceedings of the 2018 International Power Electronics Conference (IPEC-Niigata 2018 -ECCE Asia), Niigata, Japan, 20-24 May 2018; pp. 118-122. 
9. Li, M.; Chen, Q.; Ren, X.; Zhang, Y.; Jin, K.; Chen, B. The integrated LLC resonant converter using center-tapped transformer for on-board EV charger. In Proceedings of the 2015 IEEE Energy Conversion Congress and Exposition (ECCE), Montreal, QC, Canada, 20-24 September 2015; pp. 6293-6298.

10. Park, K.B.; Kim, B.C.; Lee, B.H.; Kim, C.E.; Moon, G.W.; Youn, M.J. Analysis and design of LLC resonant converter considering rectifier voltage oscillation. In Proceedings of the 2009 IEEE Energy Conversion Congress and Exposition, San Jose, CA, USA, 20-24 September 2009; pp. 771-775.

11. Park, K.; Lee, B.; Moon, G.; Youn, M. Analysis on Center-Tap Rectifier Voltage Oscillation of LLC Resonant Converter. IEEE Trans. Power Electron. 2012, 27, 2684-2689. [CrossRef]

12. Lee, B.H.; Kim, M.Y.; Kim, C.E.; Park, K.B.; Moon, G.W. Analysis of LLC Resonant Converter considering effects of parasitic components. In Proceedings of the INTELEC 2009-31st International Telecommunications Energy Conference, Incheon, South Korea, 18-22 October 2009; pp. 1-6.

13. Hariya, A.; Yanagi, H.; Ishizuka, Y.; Matsuura, K.; Tomioka, A.; Ninomiya, T. Influence of parasitic components on MHz-level frequency LLC resonant DC-DC converter. In Proceedings of the IECON 2015-41st Annual Conference of the IEEE Industrial Electronics Society, Yokohama, Japan, 9-12 November 2015; pp. 4842-4847.

14. Kim, J.H.; Kim, C.E.; Kim, J.K.; Moon, G.W. Analysis for LLC resonant converter considering parasitic components at very light load condition. In Proceedings of the 8th International Conference on Power Electronics - ECCE Asia, Jeju, South Korea, 30 May-3 June 2011; pp. 1863-1868.

15. Feng, W. State-Trajectory Analysis and Control of LLC Resonant Converters. Doctor Dissertations, Virginia Polytechnic Institute and State University, Blacksburg, Virginia, 29 March 2013.

16. Liu, J.; Zhang, J.; Zheng, T.Q.; Yang, J. A Modified Gain Model and the Corresponding Design Method for an LLC Resonant Converter. IEEE Trans. Power Electron. 2017, 32, 6716-6727. [CrossRef]

17. Ivensky, G.; Bronshtein, S.; Abramovitz, A. Approximate Analysis of Resonant LLC DC-DC Converter. IEEE Trans. Power Electron. 2011, 26, 3274-3284. [CrossRef]

18. Kwon, M.; Lee, W. A Study on the Analysis and Control of No-load Characteristics of LLC Resonant Converter for Plasma Process. In Proceedings of the 2018 International Power Electronics Conference (IPEC-Niigata 2018 -ECCE Asia), Niigata, Japan, 20-24 May 2018; pp. 114-117.

19. Kim, J.H.; Kim, C.E.; Kim, J.K.; Lee, J.B.; Moon, G.W. Analysis on Load Adaptive Phase-Shift Control for High Efficiency Full-Bridge LLC Resonant Converter in Light Load Conditions. IEEE Trans. Power Electron. 2016, 31, 4942-4955. [CrossRef]

20. Ahmed, M.R.; Todd, R.; Forsyth, A.J. Analysis of SiC MOSFETs under hard and soft-switching. In Proceedings of the 2015 IEEE Energy Conversion Congress and Exposition (ECCE), Montreal, QC, Canada, 20-24 September 2015; pp. 2231-2238.

21. Ahmed, M.R.; Todd, R.; Forsyth, A.J. Predicting SiC MOSFET Behavior Under Hard-Switching, SoftSwitching, and False Turn-On Conditions. IEEE Trans. Ind. Electron. 2017, 64, 9001-9011. [CrossRef]

22. Infineon Technologies. Design Guide for LLC Converter with ICE2HS01G. Application Note, V1.0. Available online: https://www.infineon.com/dgdl/Infineon-DesignguideLLC_converterICE2HS01G-AN-v0100-EN. pdf?fileId=db3a304330f68606013103ebd94f3e98 (accessed on 1 July 2011).

23. Wu, X.; Chen, H.; Qian, Z. 1-MHz LLC Resonant DC Transformer (DCX) With Regulating Capability. IEEE Trans. Ind. Electron. 2016, 63, 2904-2912. [CrossRef]

(C) 2019 by the authors. Licensee MDPI, Basel, Switzerland. This article is an open access article distributed under the terms and conditions of the Creative Commons Attribution (CC BY) license (http://creativecommons.org/licenses/by/4.0/). 